\title{
C@rtas Ácidas e Críticas: a "ombudsmania" pelas narrativas e visão singular da Campanha de 1998 e do primeiro mandato de Lula ${ }^{1}$
}

\author{
Boanerges Balbino LOPES FILHO ${ }^{2}$
}

\begin{abstract}
Resumo:
A análise da mídia, condutora ideológica da oposição ao governo do presidente Luís Inácio Lula da Silva, é destaque nas Cartas Ácidas e Críticas em 1998 e entre os anos 2003 e 2006, períodos em que o jornalista e professor Bernardo Kucinski atuou junto às caravanas da cidadania e como assessor especial de Comunicação da Presidência, no primeiro mandato. Escritos diariamente e entregues ao presidente logo cedo, os informativos comentavam de forma direta e crítica os principais temas veiculados nos meios de comunicação e que viriam a ser decisivos na vida do Brasil e dos brasileiros. Problematiza-se no artigo dissonâncias nos relacionamentos entre o governo federal e meios de comunicação, além do papel desenvolvido por Kucinski em questões internas em que não fica claro se as atividades são efetivas de ombudsman/ouvidor ou de um crítico de mídia. Pondera-se no texto ainda que a intenção predominante de autocrítica interna estabelece um paradoxo: sinaliza para mudanças na realidade governamental, mas aponta para ações de marketing político e eleitoral.
\end{abstract}

Palavras-chave: Cartas ácidas e críticas. Provedor de Justiça. Governo Lula. Marketing político e eleitoral.

\section{Acid and Critical Letters: the "ombudsmania" for the narratives and unique vision of the 1998 Campaign and Lula's first term}

\begin{abstract}
:
The analysis of the media, an ideological driver of the opposition to the government of President Luís Inácio Lula da Silva, is highlighted in the Acid and Critical Letters in 1998 and between the years 2003 and 2006, a period in which the journalist and professor Bernardo Kucinski worked with the caravans of citizenship and as special communication advisor to the Presidency in the first term. Written daily and delivered to the president early on, the newsletters commented directly and critically on the main themes conveyed in the media and which would become decisive in the lives of Brazil and Brazilians. The article discusses dissonances in the relationships between the federal government and the media, in addition to the role developed by Kucinski in internal issues in which it is not clear whether the activities are effective as an ombudsman / ombudsman or a media critic. It is considered in the text that the predominant intention of internal self-criticism establishes a paradox: it signals changes in the governmental reality but points to political and electoral marketing actions.
\end{abstract}

Keywords: Acid and Critical Cards. Ombudsman. Lula government. Political and electoral marketing.

\footnotetext{
1 Uma versão preliminar do texto foi publicada nos Anais do $16^{\circ}$ Encontro Nacional de Pesquisadores em Jornalismo, SBPJor. Disponível http://sbpjor.org.br/congresso/index.php/sbpjor/sbpjor2018/paper/view/1698

2 Jornalista e Professor Titular da Faculdade de Comunicação da Universidade Federal de Juiz de Fora (UFJF-MG). Coordenador do curso de especialização em Comunicação Empresarial da instituição desde 2006. Conselheiro da Associação Brasileira de Ensino de Jornalismo (Abejor). Doutor em Comunicação e Cultura pela Universidade Federal do Rio de Janeiro (UFRJ) e Mestre em Comunicação pela Universidade Metodista de São Paulo (Umesp).E-mail: bblopes@globo.com
} 


\title{
Grietas ácidas y críticas: "ombudsmania" para las narrativas y la visión singular de la Campaña de 1998 y el primer mandato de Lula
}

\begin{abstract}
Resumen:
El análisis de los medios, un impulsor ideológico de la oposición al gobierno del presidente Luís Inácio Lula da Silva, se destaca en las Acid and Critical Letters en 1998 y entre los años 2003 y 2006, un período en el que el periodista y profesor Bernardo Kucinski trabajó con las caravanas de ciudadanía y como asesor especial de comunicación de la Presidencia en el primer mandato. Escrito diariamente y entregado al presidente desde el princípio, los boletines informaron directa y críticamente sobre los principales temas transmitidos en los medios y que serían decisivos en la vida de Brasil y los brasileños. El artículo discute las disonancias en las relaciones entre el gobierno federal y los medios de comunicación, además del papel desarrollado por Kucinski en asuntos internos en los que no esta claro si las actividades son efectivas como defensor del pueblo / defensor del pueblo o crítico de los medios. Se considera en el texto que la intención predominante de la autocrítica interna establece una paradoja: señala cambios en la realidad gubernamental pero apunta a acciones de marketing político y electoral.
\end{abstract}

Palabras clave: Letras ácidas y críticas. Defensor del pueblo. Gobierno de Lula. Comercialización política y electoral.

O poder inebria as pessoas. Por isso, a Carta Crítica era importante. Porque quem está perto do presidente fica meio inibido para criticar, às vezes. De falar: "olha, presidente, quem sabe..." Bernardo Kucinski

\section{Introdução}

Uma breve constatação de início. Indicativa da relevância do tema abordado. Das organizações de educação e saúde, passando por shoppings e bancos, a instituição ombudsman (também denominada ouvidoria ${ }^{3}$ ), na contemporaneidade, está consolidada em diversos setores, inclusive o governamental. Nem a extinção do cargo de public editor (equivalente ao ombudsman), no The New York Times, anunciado em maio de 2017 e recebido com críticas pelos profissionais que ocupam a função no Brasil e no mundo foi capaz de abalar a importância alcançada pela função globalmente. De acordo com Gomes (1987), a admissão do ombudsman em um universo de diversificados sistemas jurídicos demonstra, de um lado, o extraordinário potencial de universalização

\footnotetext{
3 Historicamente, o ombudsman surgiu como ouvidor, na Suécia, em 1713, apresentado como "representante do Parlamento", sendo possível observar distinções entre os termos conforme foi sendo implantando em países e organizações distintas (MOLINA, 2011). Segundo Faria Mendes (2002), muitos meios de comunicação dão outras denominações aos profissionais que realizam o trabalho de ombudsman. Na Espanha (e na maioria dos países de língua espanhola), em jornais como El País e La Vanguardia, ele é chamado de "Defensor do leitor"; na França, no Le Monde, Le Progres e France 3, de "Mediador"; e em Portugal, no Diário de Notícias e Público, de "Provedor dos Leitores". Mas a ABO, representante oficial na atualidade dos profissionais que atuam nos setores no Brasil, praticamente não distingue entre as denominações, ao definir sua razão social como Associação Brasileira de Ouvidores/Ombudsman. (vide: http://www.abonacional.org.br/estatuto). Ver também sobre o tema Braz e Varão (2012, p. 57).
} 
do instituto e, de outro, a necessidade de se implementarem os mecanismos clássicos de controle da administração (interno, jurisdicional e parlamentar).

Assim posto, dimensionado apropriadamente e delimitado em período temporal, de lugar e atuação, o espaço governamental e o profissional lá atuante tornam-se o objeto principal das reflexões contidas no artigo. Leva-se em conta para tal a pesquisa denominada "Estudo para medir o conhecimento e uso do serviço de ouvidoria entre os brasileiros", realizada pelo Instituto DataFolha, em conjunto com a Associação Brasileira de Ombudsman/Ouvidoria (ABO), entre 04 e 14 de setembro de 2017, envolvendo 2.076 entrevistas com pessoas de 16 anos ou mais, em 149 municípios.

No estudo, constatou-se que a taxa de conhecimento do que se constitui uma ouvidoria é alta, já que dois em cada três brasileiros adultos (67\%) já ouviram falar no termo, principalmente os mais ricos e mais instruídos - entre estes o índice alcança, respectivamente, $82 \%$ e $90 \%$. Um outro ponto interessante da pesquisa demonstra que a maioria $(71 \%)$ nunca estabeleceu contato com alguma ouvidoria por não ter necessidade. Da parcela que precisou buscar apoio em uma ouvidoria ou ombudsman (29\%), destacam-se os segmentos dos mais instruídos (52\%) e dos mais ricos (46\%). Ao serem questionados sobre o motivo principal do relacionamento com um desses setores, atribuíram que foi o de fazer "uma reclamação" e, em $73 \%$ dos casos, ela foi resolvida. "Pedir informação" foi citado por $21 \%$ entre outras respostas menos lembradas. Independente ou não da disponibilidade de um núcleo de ombudsman ou ouvidoria, a avaliação da relevância é positiva: para 77\%, o trabalho deles é muito importante.

De acordo ainda com o Relatório de Gestão Exercício 2010 da Controladoria Geral da União (BRASIL, 2011), a ouvidoria pública tornou-se, em pouco tempo, imprescindível para caracterizar a natureza democrática do Estado Brasileiro (COELHO, 2012). Segundo o documento, de 2003 até meados de 2010, houve um aumento exponencial no número de ouvidorias ligadas direta ou indiretamente aos governos federal, estadual e municipal, sendo no âmbito do Poder Executivo Federal um incremento de $313 \%$ em sete anos.

Se as projeções estatísticas indicam positividade nas ações, como apontam os estudos, existem polêmicas que demarcam a atuação dos profissionais que porventura optam por funções nos setores. Muitos usuários identificam posturas de prepotência e arrogância quando recorrem em busca de soluções. Mas os que atuam nos setores costumam ser rigorosos em suas atuações, o que provoca por parte dos que cobram 
soluções, desabafos que incluem a expressão "um bando de chatos". Por exemplo: o primeiro ombudsman de imprensa no Brasil, Caio Túlio Costa, foi indicado, segundo Oliveira Santos (apud FARIA MENDES, 2002, p. 39), pelo jornalista Leão Serva para ocupar o cargo na Folha de S. Paulo - após a recusa de quatro outros profissionais não apenas por ser um bom secretário de redação, mas, sim, por ser considerado entre os colegas um "chato". E, não à toa, o jornalista Bernardo Kucinski, foi assim denominado por Lula.

Kucinski (2000, p. 16) expressou publicamente, em algumas ocasiões, que todo governo precisa não só de um, mas de vários chatos: "A tendência é de um governante ver-se rodeado de puxa-sacos. Daí a importância dos chatos...". A denominação, inclusive, extrapolou os corredores do Planalto e ganhou a mídia. Em matéria publicada em dezembro de 2005 pela Agência Repórter Social, a jornalista Alice Sosnoswki se refere ao documento, naquele momento já alterado para "Carta Crítica", e cita o "chato do Kucinski”, tornando assim visível o apelido pelo qual era conhecido nos corredores, em Brasília. No texto, a jornalista, a despeito da "chatice", reconhece o resultado do trabalho e escreve que Kucinski tece comentários sobre as ações do governo, suas repercussões e analisa as matérias da imprensa no que elas trazem de mais interessante: as entrelinhas.

Nesse fazer diário, as manifestações de resistência também partem diretamente da imprensa. Alguns jornalistas, ao tecer suas críticas, interpretam que o ombudsman em seu desempenho também questionador das atividades jornalísticas, tentam "ensinar" jornalismo a quem sabe. Ou acreditam poder determinar o que é mais importante ou não para os veículos. Na verdade, segundo Lins da Silva ${ }^{4}$ (2006, não paginado), ombudsman da Folha de S. Paulo de 2008 a 2010, jornalista gosta de criticar: "Mas não de autocriticar-se ou de receber críticas". Por conta disso, deduz o jornalista e professor, mesmo com o avanço histórico, o instituto do ombudsman se restringe a poucos órgãos jornalísticos numa perspectiva mundial, algo que se acentua diante do quadro de precarização na atualidade que abrange de maneira ampla os locais de exercício profissional. Além disso, toda uma transformação que vem se processando no século XXI com a expansão tecnológica, a mobilidade digital, mas também mesclada de dificuldades de expansão de postos de trabalho e um aumento da subserviência, acaba por distanciar os profissionais de imprensa dos verdadeiros anseios da sociedade.

${ }_{4}^{4}$ Texto sem título, publicado na primeira orelha do livro Ombudsman, o relógio de Pascal, em edição revista e atualizada com dois capítulos novos, em 2006, de autoria de Caio Túlio Costa. 
Kucinski deixa claro isso em entrevista ao jornal Correio Brasiliense:

\begin{abstract}
Se falamos de jornalismo, é preciso considerar que a mídia clássica dos grandes jornais, diários impressos e o jornalismo clássico, que detinha o monopólio da mediação, estão em crise profunda, talvez terminal. Nesse quadro de crise, o jornalismo brasileiro foi mais afetado do que o jornalismo que nos era referencial. O americano, por exemplo, ou o britânico, ou o francês. Isso se deu porque além da precarização do ofício, a grande mídia embarcou na campanha do golpe, arrastando consigo a maioria de seus jornalistas. A mídia internacional, até por seu distanciamento das paixões locais, viu com clareza o que estava se passando e não embarcou no golpe. (KUCINSKI apud DAEHN, 2016, não paginado).
\end{abstract}

A grande imprensa brasileira, ainda na opinião de Kucinski (2014), é parte do bloco de poder, não se distinguindo deste.

\begin{abstract}
Quando eu digo bloco do poder, eu não digo quem está governando naquele momento, mas o sistema de forças que mandam nas riquezas do país, nas terras, nos recursos. Por ser parte do bloco do poder, ela não consegue exercer o papel de mediadora, porque ela é o próprio poder". O que a insere entre características que demarcam a América Latina, onde se destaca o lugar da imprensa no bloco do poder (KUCINSKI, 2014, p. 20).
\end{abstract}

Durante longo período, entre as décadas de 1960 e 1980, estruturas autoritárias predominaram em alguns países, entre eles o Brasil, provocando cerceamento do direito de defesa do indivíduo diante do Estado. Atrelado a um intenso estrangulamento do acesso do cidadão ao controle e avaliação da gestão pública, o aparelho administrativo permaneceu asfixiado. Mas a história recente tem demonstrado que uma das características básicas da instituição do ombudsman é justamente a postura de guardiã dos direitos dos cidadãos da administração pública. Em determinados países, o ombudsman tem se consagrado como um profissional na luta contra o que se popularmente define como "lentocracia" ou "burrocracia" e, também, na resistência para transpor a tirania burocrática, decorrente da crescente complexidade das instâncias do Estado sobre a sociedade atual. O que gera metaforicamente um "tiroteio" de ideias e ações no campo político, onde se formaliza a indagação primordial sobre o verdadeiro papel por ele exercido: o de um agente de mudanças ou mero marqueteiro?

De acordo com a pesquisadora Rosas (2015), em setembro de 1998, o exombudsman do diário cearense $O$ Povo, jornalista Lira Neto, escreveu um artigo questionando se os leitores consideravam o ombudsman seu representante ou, como pensam alguns críticos, o cargo era apenas uma tática dos jornais para mostrarem ao público que são transparentes. Segundo Lira Neto (2000, texto de apresentação da obra), 
se tomarmos como referência a mídia em geral, a pergunta fica no ar: "O representante do leitor não passa mesmo de uma estratégia de marketing para apaziguar os ânimos de leitores indignados?” Rosas (2015, p. 128) tem seu próprio questionamento: “Afinal, o ombudsman é mesmo só uma ação estratégica?"

A respeito algumas questões a serem tratadas no transcorrer do texto: no caso da realidade governamental, qual o papel deve desempenhar o responsável por atividades que se relacionam originalmente com o "representante do povo"? Será que a ouvidoria no Brasil, por estar situada no seio da Administração Pública, não tem sua condição de independência funcional duvidosa? A inexistência de um ombudsman nacional é justamente face às características do nosso sistema federativo e outras alegorias? Tentaremos avançar em algumas condições reflexivas.

\section{Breve histórico}

Para a imprensa, foi uma belíssima lição. Mas foi uma lição muito dura, porque a função não ganhou o coração da imprensa brasileira. Caio Túlio Costa $^{5}$

Segundo Lopes (2004), a figura do ouvidor está presente no Brasil desde 1538. O capitão-mor Antonio de Oliveira foi pioneiro. Nomeado, passou a acumular os dois cargos na Capitania de São Vicente. Mas a onda da "ombudsmania" só foi impulsionada no Brasil quatro séculos e meio depois, a partir dos anos 1980, quando o usuário passou a "redescobrir" seus direitos. Direitos não só de consumidor, mas de consumerista ${ }^{6}$, numa onda originada a partir dos EUA. Em 1985, a Rhodia deu o pontapé inicial na área privada e incorporou a função a seus quadros. No ano seguinte surgiu a primeira Ouvidoria Pública em Curitiba (PR), pelo Decreto-Lei n ${ }^{\circ} 215$. Nos anos 1990, a Universidade Federal do Espírito Santo (UFES/ES) deu início a atividade na área de educação, mesmo período em que passou a vigorar o Código de Defesa do Consumidor, reforçando o compromisso das organizações com a cidadania, e, consequentemente,

\footnotetext{
5 Tornou-se, em 24 de setembro de 1989, o primeiro ombudsman da imprensa brasileira, cargo que ocupou até 22 de setembro de 1991 (LOPES, 2004).

${ }^{6}$ Desde meados do séc. XX têm se ampliado por todo o mundo diversos movimentos e organizações de defesa do consumidor que procuram legitimar os seus direitos e contribuir para maior qualidade dos produtos e serviços e, simultaneamente, promover o desenvolvimento sustentável. Portanto, toma-se aqui o termo "Consumerismo" como maneira de designar um tipo de atitude oposta ao consumismo e que se caracteriza por um consumo racional, controlado e responsável, levando-se em conta as consequências económicas, sociais, culturais e ambientais do próprio ato de consumir (LOPES, 2004). Giacomini Filho (1991) e outros autores em Portugal e no Brasil adotam o conceito.
} 
consolidando a participação do ombudsman/ouvidor na sociedade brasileira (LOPES, 2004).

No caso específico da área governamental, dados do Instituto de Pesquisa Econômica Aplicada constantes na página da ouvidoria do TRT 14ª (2006) apontam que até 2002 , no país, havia apenas 40 ouvidorias vinculadas ao governo federal, número que triplicou em dois anos, chegando a 120 organizações em 2006. Segundo estimativa da Associação Brasileira de Ouvidores/Ombudsman (criada em março de 1995), existem hoje, no Brasil, mais de dois mil ouvidores e ombudsmen em atividade. Embora a expansão proporcione a presença de profissionais nas mais diversas áreas possíveis, algumas confusões são observadas. Por exemplo: a figura do ombudsman é identificada com o Serviço de Atendimento ao Consumidor (SAC). Também há distorções quando se tenta caracterizar as duas vertentes. ${ }^{7} \mathrm{Na}$ opinião de Gomes de Matos (2006), entre outros profissionais, a diferença não está no nome. A diferença está no objetivo específico de cada setor e de cada órgão: defender um serviço justo para o cliente, defender o cidadão ou defender a qualidade do jornalismo a que o público tem direito.

\section{Dúvidas e conflitos}

Nunca fui censurada ou pressionada enquanto avaliava o jornal, mas, confesso: é uma situação ruim ter que criticar seus próprios colegas. E, apesar de minha total liberdade, não tenho nenhum poder.

Apesar do reconhecimento mundial, dúvidas e conflitos provocados sobre a atuação desse profissional permaneçam presentes na mídia e nos governos.

Imprescindível ponderar que pelo fato da Comissão de Estudos Constitucionais não ter considerado efetivamente a proposta de instituição do Defensor do Povo (Ombudsman) no Brasil, a emenda aprovada durante a elaboração da Constituição Brasileira de 1988 descentralizou a Ouvidoria. Com isso, a partir dela, qualquer setor do poder executivo poderia (pode), por lei ou decreto, estabelecer a sua Ouvidoria. Por um lado, a bel-prazer do dirigente, isso fez com que o país ficasse, durante um bom tempo sem contar com instrumentos de defesa dos direitos do cidadão, notadamente no âmbito da administração pública federal. Por outro, se fosse instituída apenas como Ouvidoria Geral, como se pretendia inicialmente, ela se reportaria somente ao parlamento. Somado

\footnotetext{
7 Didaticamente, as diferenças podem ser observadas no blog A bordo da comunicação (s.d.). Disponível em: http://abordorp.blogspot.com/2009/06/sac-e-ouvidoriaombudsman.html. Acesso em: 9 jul. 2018 8 Ombudsman no período de 24 de abril de 2010 a 27 de abril de 2014 da Folha de S. Paulo.
} 
a isso, deu-se, de maneira perceptível, um crescimento desordenado, oscilando entre ações e reações exponenciais de alguns órgãos do Estado pela instituição de ouvidores e, em outros, não.

Assim, com e sem legitimação normativa, foram sendo atribuídos formatos institucionais díspares, com os mais diferenciados níveis de autonomia, ou de subordinação, em relação ao gestor (PINTO LYRA, 2018). O advogado, ex-presidente da Associação Brasileira de Ouvidores e ex-ouvidor Geral do Estado do Paraná, João Elias de Oliveira, descreve algumas das diferenças que demarcam dificuldades e singularidades em ouvidorias no país:

\begin{abstract}
Desde as primeiras experiências e no trilhar em busca de um modelo adequado à nossa realidade, a ouvidoria brasileira esqueceu as teorias acadêmicas e as sólidas restrições impostas pelo ombudsman inspirador. Nosso caminho traçou um desenho eficiente e condizente com o cotidiano operacional e cultural dos organismos. Assim, bem claro fica a distinção entre o ombudsman tradicional e a ouvidoria brasileira que, apesar de terem adotado conceitos parecidos e similares nas suas ações operacionais, definitivamente não podem ser considerados como instituições iguais. $\mathrm{O}$ diferencial é que o ombudsman transita do lado externo da administração, uma figura individual e não um coletivo, obrigatoriamente indicado, eleito ou apontado pelo Parlamento. Possui independência plena e autonomia de ação, mandato fixado e, na maioria dos países, ocupa-se da defesa dos interesses e direitos dos cidadãos. Temos uma configuração diferente. Ao contrário do ombudsman, a quase totalidade das ouvidorias públicas brasileiras tem como característica principal o fato de serem órgãos integrantes da Administração, exercendo as suas ações de modo individual como um Ouvidor ou então como um sistema ou rede, usando a reclamação para garantia do controle interno das instituições. Em seu agir, assume a representação do cidadão na sua qualidade de usuário e destinatário do serviço público (OLIVEIRA, s.d., não paginado).
\end{abstract}

A experiência vivida durante o primeiro mandato do presidente Lula fez com o professor Bernardo Kucinski percebesse algo que aprendeu dentro do governo, e pela observação das experiências de outros países. Se relaciona à seguinte constatação: "Um presidente é uma usina de tomada de decisões, ele decide sobre vários assuntos todo o tempo. Precisa de informações para fundamentar essas decisões e para isso nós produzimos sínteses dos noticiários regional, nacional e internacional" (KUCINSKI apud POR UMA COMUNICAÇÃO..., 2012, não paginado). No entanto, ressalta o jornalista, as sínteses precisam ser exatas, descartando-se informações supérfluas, desnecessárias, onde é preciso ter o estritamente necessário sobre cada assunto. Lembra ainda que é imprescindível a função de saber o que está sendo dito sobre o governo, acompanhando a mídia. 
O ombudsman, associado paralelamente a algumas iniciativas dos meios de comunicação, define considerações possíveis e reflexivas para a proposta do que aqui é refletido. A jornalista Junia Nogueira de Sá, ombudsman da Folha no período 1993-94, atualmente consultora e especialista em gestão empresarial, concepção, planejamento e implantação de programas de relacionamento institucional, diz que são muitas as dificuldades para o exercício do cargo: "Descobri, logo de início, que ser ombudsman significa reservar boa parte do tempo para explicar aos outros o que é ser ombudsman. Principalmente a estudantes e novos leitores" (SÁ apud LOPES, 2004, p. 24).

Para Ajzenberg ${ }^{9}$ (apud LOPES, 2004, p. 3) que também já ocupou o cargo na Folha, "embora mudanças tenham ocorrido há anos, continua sendo muito difícil por parte dos jornalistas, de maneira geral, admitir um mínimo de culpabilidade em relação aos erros, mais ou menos relevantes, cometidos". Giangrande ${ }^{10}$ (apud LOPES, 2004, p. 4) que instituiu a função no Grupo Pão de Açúcar, sempre deixou claro que é melhor não ter ombudsman do que manter uma instituição falsa: "Um ombudsman só como jogada de marketing pode acabar com a imagem da instituição, pois não se trata apenas de cumprir o código, mas de firmar compromisso com a cidadania, com o papel social do outro".

O jornalista Caio Túlio Costa, autor no Brasil do primeiro livro sobre a atividade, $O$ relógio de Pascal, diz que mudou a situação do jornalista, não o papel do jornalista. Segundo Túlio Costa (2006), antes ele era o ator principal. Hoje é o coadjuvante. Destaca que o profissional atua no sentido de ser uma espécie de moderador entre o público e os atos, mas tem uma concorrência que nunca teve. Portanto, hoje, qualquer pessoa pode publicar uma informação ou opinião. Ele considera, assim, como grande vantagem a incorporação do ombudsman no jornalismo, o estímulo à precaução dos profissionais antes de decidirem fazer ou dizer o que não estiver dentro de preceitos éticos e reais. Isso reforça a necessidade de o jornalista continuar fazendo aquilo para o qual ele está tecnicamente preparado, que é levantar os fatos de maneira independente, com capacidade objetiva de análise e voltado para o

\footnotetext{
9 Bernardo Ajzenberg é jornalista, escritor e tradutor. Trabalhou em publicações como Veja, Gazeta Mercantil e, na Folha, foi ombudsman de 18 de março de 2001 a 07 de março de 2004.

10 Vera Giangrande foi a primeira mulher a obter cargo de gerência em relações públicas em uma empresa norte-americana. Graduada em Biblioteconomia, Jornalismo e Psicologia Social e Infantil. Ocupou a presidência do Conselho Regional de Profissionais de Relações Públicas, em 1983. Desenvolveu também a prática do ombudsman pelo Grupo Pão de Açúcar, a partir de 1994. O Prêmio Personalidade da Comunicação do Ano 2000 foi a última homenagem pública recebida em vida.
} 
interesse público, o que leva o jornalista - ao menos aqueles comprometidos com a profissão - a aprimorar sua postura com capacidade e independência.

Para Túlio Costa (2006, p.113-132), cuja experiência na Folha foi cercada de algumas polêmicas envolvendo outros profissionais - por exemplo, o jornalista Paulo Francis -, quando um leitor compra um jornal não vê naquele maço de papel apenas um material descartável, mas essencialmente uma coisa que acrescentará algo a sua vida. "Ele se sente gratificado quando liga para seu jornal e percebe que alguém presta atenção a suas críticas. Ele se sente parte do processo e, na verdade, é” (TÚLIO COSTA, 2006, p. 11-20).

\title{
Ácidas e críticas
}

\author{
Eu recebia cada Carta Ácida logo cedo. Quando levantava, a Carta Ácida \\ estava em cima de uma mesa; ela era mandada por computador [...] eu nem \\ precisava ler os jornais, eu lia a Carta Ácida e já sabia as cascas de banana \\ que estavam jogadas no caminho de nossa campanha. \\ Luís Inácio Lula da Silva
}

As cartas lidas para este estudo e que auxiliaram nas reflexões aqui desenvolvidas cobrem um período de 27 de julho a primeiro de outubro de $1998^{11}$, parte delas tornadas públicas por Kucinski (2000), e as compiladas do período de 2003 a 2006 e reunidas em um capítulo denominado "Relações com a Mídia" (KUCINSKI, 2014) são abordadas neste tópico com algumas inferências.

Um panorama de temas abordados pela imprensa no primeiro mandato e de alguns conflitos internos constava dos conteúdos: o programa Fome Zero; o caso Banestado; as CPIs dos Bingos e dos Correios, que investigaram o mensalão; a transposição do Rio São Francisco; a crise da febre aftosa; a economia e, claro, a comunicação (KUCINSKI, 2000). A análise da mídia, condutora ideológica da oposição ao governo Lula, ocupa lugar de destaque. Kucinski (2000) diz que começou a escrever as cartas informalmente em 1994 e passou a sistematizá-las durante as caravanas da cidadania. Foram consolidadas na campanha de 1998. "Ele (Lula) viajava com o jornalista Ricardo Kotscho e com o agrônomo, professor e escritor José Graziano e eu escrevia diariamente. O objetivo era ele estar a par do que estava se falando sobre política, sobre ele, sobre o PT na mídia” (KUCINSKI, 2000, p. 15). Para a jornalista

\footnotetext{
11 A primeira carta foi enviada no dia 27 de julho de 1998, quando o assunto quente era o escândalo da falsificação dos medicamentos. A última carta foi enviada no dia $1^{\circ}$ de outubro, já no apogeu da crise do Real. Foram 52 cartas ácidas, numeradas de 1 a 50 (com duas numerações repetidas por equívoco, conservadas com a adição de um "a" para não conflitar com os arquivos de Lula, as de número $16^{\mathrm{a}}$ e $47^{\mathrm{a}}$ ). (KUCINSKI, 2000, p. 17).
} 
Alice Sosnowski, o "ombudsman", "ouvidor" ou "crítico de mídia" do presidente esclarece como se dava a dinâmica:

A rotina do presidente Luiz Inácio Lula da Silva tem uma constante: a leitura obrigatória, todas as manhãs, de um documento conhecido como 'carta crítica'. Uma resenha do que saiu na imprensa sobre o governo naquele dia. Nela, o presidente tem acesso a uma análise apurada do noticiário. Recebe críticas, sugestões, advertências e até broncas. Algumas vezes, em seus discursos, Lula reclama da acidez dos que acordam mal-humorados. Nestas ocasiões, ele se refere ao autor da - "carta crítica" - [...] Além do presidente, poucos colaboradores têm acesso ao conteúdo da resenha. [...] $\mathrm{O}$ governo Lula ("decepcionou muito"), a imprensa ("a palavra de ordem é linchar") e os jornalistas na cobertura da crise política ("eles fazem uma cruzada moral”) (SOSNOWSKI, 2006, não paginado).

Já no governo, a partir de 2003, Kucinki estabeleceu a sequência de cartas, rebatizadas de críticas, como um trabalho que estimulasse, via fornecimento de informações analisadas e propositivas, possibilidades para que o presidente e os ministérios visassem a divulgação das ações do governo para a população, além de esclarecer o porquê de certas decisões e ações. Ele explica os motivos que o levaram a alterar a denominação das cartas:

A própria nomenclatura já tem um significado de mudança. O Lula achava que eu era ácido demais e muito mal-humorado, sempre vendo o lado negativo e então, por sugestão dele mesmo, mudamos para uma coisa mais amena, pois você pode ser crítico sem ser pessimista. O nome não mudou só porque ele virou presidente, mas já na campanha de 2002. Ele achou que não podia sair de manhã com raiva da imprensa, pensando mal das coisas, e a carta ácida realmente era ácida. Então, por exigência dele, mudamos o nome para carta crítica. No sentido de ser algo mais propositivo, menos malhumorado. [...] Começou ali a mudança de postura, uma coisa menos ácida. [...] (KUCINSKI apud SOSNOWSKI, 2006, não paginado).

Minha proposta de trabalho era a de ajudar o presidente a governar, dando seguimento, em nível de governo, à comunicação epistolar que eu havia estabelecido com Lula com razoável eficácia nos anos anteriores (KUCINSKI, 2018). ${ }^{12}$

As Cartas Críticas motivaram percepções que vão da atuação de ministros, passando pelos posicionamentos de presidentes de empresas até a participação de Duda Mendonça no governo: "ele atuou dos dois lados do balcão", enfatiza Kucinski (2014, p. 7-8). Em 2002, Duda Mendonça, o marqueteiro da vitoriosa campanha que criou o "Lulinha paz e amor", dispensou as "cartas ácidas". Mas elas foram retomadas com a vitória de Lula. Kucinski foi contratado pelo ministro Luiz Gushiken, da Secretaria de Comunicação da Presidência da República. Redigiu diariamente as cartas críticas até 30 de junho de 2006, pouco antes do final do primeiro mandato de Lula. O jornalista

12 KUCINSKI, Bernardo. Entrevista concedida ao autor em 30 jul. 2018. 
resume um pouco do impacto provocado pelos comentários contidos nas cartas durante o primeiro mandato.

\begin{abstract}
A ideia era ter uma visão independente do que acontecia, que não tivesse comprometida com interesses de um ministro ou de um grupo, e que fosse uma visão para ajudar o presidente a governar. Advertir, alertar sobre algumas coisas, chamar a atenção, resumir. Tinha que tomar cuidado porque não podia criar dissensão gratuita, mas também não podia ser uma coisa água com açúcar, porque senão ele não ia ler. Lembro de uma carta, quando era para decretar o aumento do salário mínimo, o primeiro aumento do governo Lula, e o Palocci (Antonio Palocci, Ministro da Fazenda na ocasião) não queria de jeito nenhum que aumentasse. Eles tinham aqueles argumentos econômicos, tudo fajuto, que se aumentasse aconteceria isso, a Previdência Social iria sofrer... Daí eu fiz o arrazoado mostrando exatamente o contrário. Que isso ia fazer bem até para as finanças. Teve vezes que o Palocci pediu minha cabeça. De cada três ou quatro cartas, tinha uma contra o Palocci. Ele já entrou no governo como o homem dos bancos e a primeira coisa que ele fez foi dar um cavalo de pau na economia. Tanto que, nos primeiros dois anos do governo Lula, a economia afunda. Ele era o Cavalo de Tróia do governo. Eu sempre tive essa percepção. Ele não pertencia ao ideário do PT, por isso eu o combati. (KUCINSKI apud VALENTE, 2012, não paginado).
\end{abstract}

Se o relacionamento do presidente com a mídia foi um dos pontos recorrentes nas cartas - vide caso do jornalista do The New York Times, Larry Rohter $^{13}$-, já que, segundo Kucinski (2014), o sistema de comunicação do governo era inadequado, onde a ausência de entrevistas formais e os contatos não foram permanentes com os jornalistas nos dois primeiros anos, internamente ele teve que lidar com algumas situações polêmicas e delicadas. Em ocasiões, reconhece, exageros ocorreram. Afirma que as cartas não eram neutras nem ingênuas: "Era um exercício duro e consciente que só não foi desautorizado por Lula porque tomávamos extremo cuidado nas informações e caprichávamos nos seus conteúdos didáticos” (KUCINSKI, 2014, p. 12-20). Lula, de acordo com Kucinski, via vantagens de ter esse instrumento. Dava a ele uma “alavancagem nas reuniões e nos encontros com ministros" (KUCINSKI, 2014, p. 1214). Certa ocasião, o embate se deu com o então presidente da Radiobrás, jornalista Eugênio Bucci (2008), que usou páginas do livro Em Brasília, 19 horas para tecer críticas às cartas e ao próprio Kucinski. Houve repercussão em veículos de comunicação (KAMEL, 2008).

Bucci discute as "Cartas Críticas", uma análise diária sobre mídia que Bernardo Kucinski, então assessor de Lula, escrevia para o presidente. Bucci se indignou com duas referências negativas de Kucinski à Radiobrás. A

${ }^{13}$ Expulsão de jornalista do NYT repercute no mundo. Disponível em: https://bit.ly/2JPHaGV. Acesso em: 12 jul. 2018.

Jornalista do "NYT" se retrata, e governo revoga expulsão. Disponível em: https://bit.ly/2ObuX2y. Acesso em: 12 jul. 2018. 


\begin{abstract}
primeira coisa a notar é que a reação de Bucci foi imediata: ele, que se diz um democrata, tratou de propor o afastamento de seu crítico do Conselho da Radiobrás logo depois da primeira crítica, uma atitude típica do discurso autoritário que ele diz denunciar. A primeira manifestação de Kucinski foi em dezembro de 2004 e criticava a Radiobrás por não ter mandado alguém ao Haiti cobrir o envio de novas tropas brasileiras àquele país: "Se não desenvolvermos e não disseminarmos a nossa visão dos fatos, perderemos a batalha da informação" (KAMEL, 2008, não paginado).
\end{abstract}

As cartas eram uma comunicação unilateral, rebate Kucinski (2014, p. 17-18): "De mim para o presidente, com vistas para alguns ministros. Não se pediam nem se esperavam reações ou respostas". Ele admite que influenciaram diversos processos decisórios e tenta amenizar os conflitos provocados ao circunscrever que em apenas "duas ou três ocasiões provocaram mal-estar e consequentemente admoestações".

\title{
Considerações finais
}

Pelas cartas, Kucinski não só foi propositivo como claramente influenciou em decisões do próprio presidente, a ponto de Dulci (apud KUCINSKI, 2014, p. 21) ${ }^{14}$ afirmar que o informativo havia se tornado para Lula "a única janela para o mundo". $\mathrm{Na}$ avaliação do professor, "as cartas levaram ao presidente aportes de conhecimento e informação valiosos e em fluxo contínuo, ao passo que os desacertos foram poucos e pontuais". É possível perceber concordâncias em vários escritos "entre o que as cartas recomendavam e o que ocorria como ações em dias posteriores" (KUCINSKI, 2014, p. 21-22).

Apesar das reclamações explícitas do jornalista, como a de que "pouco do que propus foi aproveitado por falha do próprio governo e também pela postura da imprensa, desacostumada e desinteressada numa relação institucional de caráter republicano" (KUCINSKI, 2014, p. 467-471), o “ombudsman/ouvidor” do presidente redigiu algumas propostas antes de solicitar exoneração do governo que o distanciam de um mero agente de marketing. Entre elas estão a do vale-jornal, que daria a todo cidadão sem recursos suficientes um vale para receber o jornal de sua preferência, a do programa de apoio à consolidação de veículos sem fins lucrativos e a de criar um sistema de comunicação pública que permanece não existindo. Para Kucinski (2014),

\footnotetext{
${ }^{14}$ Ministro-chefe da Secretaria-Geral da Presidência da República durante os oito anos de governo Lula. Atualmente, como diretor do Instituto Lula, é responsável pela Iniciativa América Latina. Um dos fundadores do Partido dos Trabalhadores (PT), membro da primeira Executiva Nacional. Fez parte da primeira bancada de deputados federais do PT (1983-1987). Presidiu a Fundação Perseu Abramo (19962003). Foi um dos coordenadores da campanha de 2002 e vice-presidente e secretário-geral do PT (KUCINSKI, 2014).
} 
um sistema que atenda a necessidade do Estado de se comunicar e que se contraponha a uma imprensa oligárquica e hostil perante um governo popular.

O ex-presidente Lula, após a campanha de 1998 e, também, durante o primeiro mandato, sugeriu que as "Cartas Ácidas" fossem publicadas mesmo que Kucinski (2000) tenha deixado claro que nunca se propôs a cobrar, vigiar, fiscalizar, nem mesmo a aconselhar. $\mathrm{Na}$ opinião do jornalista e professor, as cartas municiavam o presidente com informações e análises em linguagem objetiva, econômica, em tempo hábil e com liberdade de expressão, "o que o sistema burocrático, por sua natureza cautelosa, não consegue" (KUCINSKI, 2000, p. 15-16). Mas, Lula, de acordo com o relato do jornalista, considerou que mais do que auxiliar os candidatos do partido, elas - as cartas - poderiam permitir que se acompanhasse com atenção o tipo de jornalismo que se faz no Brasil: "Quando você assiste um programa de TV, ouve noticiário no rádio, lê um artigo, você tem a impressão que está num país onde a imprensa age democraticamente, onde a imprensa é livre, onde se tem acesso a tudo. Mas, infelizmente não é assim e as Cartas mostram isso" (KUCINSKI, 2000, p.14).

\section{Referências}

ASSOCIAÇÃO BRASILEIRA DE OUVIDORES/OMBUDSMAN; INSTITUTO DATAFOLHA. Estudo para medir o conhecimento e uso do serviço de ouvidoria entre os brasileiros. Pesquisa realizada entre 04 e 14 de setembro de 2017. Disponível em: http://www.abonacional.org.br/files/pesquisa-datafolha-abo.pdf. Acesso em: 7 jul. 2018.

ASSOCIAÇÃO BRASILEIRA DE OUVIDORES/OMBUDSMAN. Estatuto. 29 set. 2005. Disponível em: http://www.abonacional.org.br/estatuto.

BRASIL. Controladoria Geral da União - Secretaria Executiva. Relatório de Gestão Exercício 2010. Brasília, 2011. Disponível em: http://www.oas.org/juridico/PDFs/mesicic4_bra_relatorio.pdf. Acesso em: 1 jul. 2018.

BRAZ, Ailim; VARÃO, Rafiza. O papel das ouvidorias na comunicação organizacional. In: IASBECK, Luiz Carlos Assis (org.). Ouvidoria, mídia organizacional. Porto Alegre: Sulina, 2012. p. 57-77.

BUCCI, Eugênio. Em Brasília, 19 horas - a guerra entre a chapa-branca e o direito à informação no primeiro governo Lula. Rio de Janeiro: Editora Record, 2008.

COELHO, Sylvia Regina dos Santos. Representatividade e representações em ouvidorias públicas. IASBECK, Luiz Carlos Assis (org.). Ouvidoria, mídia organizacional. Porto Alegre: Sulina, 2012. p. 95-112.

DAEHN, Ricardo. Bernardo Kucinski fala sobre ditadura, política e religião na Bienal. 


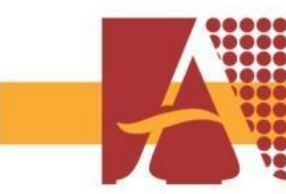

Correio Brasiliense, 23 out. 2016. Disponível em: https://www.correiobraziliense.com.br/app/noticia/diversao-earte/2016/10/23/interna_diversao_arte,554335/bernardo-kucinski-fala-sobre-ditadurapolitica-e-religiao-na-bienal.shtml. Acesso em: 11 jun. 2018.

FARIA MENDES, Jairo. O ombudsman e o leitor. Belo Horizonte: Editora O Lutador, 2002.

GIACOMINI FILHO, Gino. Consumidor versus propaganda. São Paulo: Summus Editorial, 1991.

GOMES, Manoel Eduardo Alves Camargo e. A institucionalização do ombudsman no Brasil. Revista de Direito Administrativo, Rio de Janeiro, v. 167, p. 1-21, fev. 1987. Disponível em: http://bibliotecadigital.fgv.br/ojs/index.php/rda/article/view/45462/43868. Acesso em: 16 jul. 2018.

GOMES DE MATOS, Gustavo. A cultura do diálogo. Rio de Janeiro: Elsevier, 2006.

KAMEL, Ali. Chapa branca. O Globo, 21 abr. 2008. Disponível em [para assinantes]: https://oglobo.globo.com/in/chapa-branca-3976034. Acesso em: 12 jul. 2018.

KUCINSKI, Bernardo. Cartas a Lula - o jornal particular do presidente e sua influência no governo do Brasil. Rio de Janeiro: Edições de Janeiro, 2014.

KUCINSKI, Bernardo. As c@ rtas ácidas da campanha de Lula de 1998. São Paulo: Ateliê Editorial, 2000.

LINS DA SILVA, Carlos Eduardo. [Texto da primeira orelha do livro]. In: TÚLIO COSTA, Caio. Ombudsman: o relógio de Pascal. Ed. rev. e aum. São Paulo: Geração Editorial, 2006.

LIRA NETO. A herança de Sísifo: da arte de carregar pedras como ombudsman na Imprensa. Fortaleza: Edições Demócrito Rocha, 2000.

LOPES, Boanerges. 'Ombudsmania' chega à TV. Observatório da Imprensa, edição 297, 5 out. 2004. Disponível em: http://observatoriodaimprensa.com.br/interessepublico/ombudsmania-chega-a-tv/. Acesso em: 2 jul. 2018.

LOPES, Boanerges. O que é assessoria de imprensa. São Paulo: Brasiliense, 2003.

MOLINA, Diogo. Ombudsman, sua origem. Observatório da Imprensa, edição 672, 13 dez. 2011. Disponível em: http://www.observatoriodaimprensa.com.br/feitosdesfeitas/ed672-ombudsman-sua-origem/. Acesso em: 9 jul. 2018.

OLIVEIRA, João Elias de. Ouvidoria pública brasileira: a evolução de em [sic] modelo único. Universidade Federal de Goiás - Ouvidoria. Goiânia, s.d. Disponível em: https://ouvidoria.ufg.br/n/29905-ouvidoria-publica-brasileira-a-evolucao-de-emmodelo-unico. Acesso em: 12 jun. 2018.

PINTO LYRA, Rubens. A ouvidoria pública: características, transformações e 
perspectivas. 2018. Disponível em: https://bit.ly/2AdhzI6. Acesso em: 6 jul. 2018.

POR UMA COMUNICAÇÃO pública de verdade. Forum, [Santos-SP], 2 fev. 2012. Disponível em: https://revistaforum.com.br/noticias/por_uma_comunicacao_publica_de_verdade/. Acesso em: 11 jun. 2018.

ROSAS, Juliana de Amorim. O ombudsman entre liberdades, políticas e estratégias. Communicare, São Paulo, v. 15, n. 1, p. 126-142, $1^{\text {o }}$ sem. 2015. Disponível em: https://casperlibero.edu.br/wp-content/uploads/2016/08/O-ombudsman-entreliberdadespoliticas-e-estrategias.pdf. Acesso em: 2 jul. 2018.

SOSNOWSKI, Alice. Bernardo Kucinski: Lula eliminou a necessidade da imprensa. Observatório da Imprensa, edição 363, 10 jan. 2006. [Publicado antes na Agência Repórter Especial]. Disponível em: http://www.observatoriodaimprensa.com.br/imprensa-em-questao/lula-eliminou-anecessidade-da-imprensa/. Acesso em: 16 jun. 2018.

TRT $14^{\mathrm{a}}$ REGIÃO - JUSTIÇA DO TRABALHO. Dados estatísticos - Ouvidoria. 2006. Disponível em: https://portal.trt14.jus.br/portal/ouvidoria/dados-estat-sticos. Acesso em: 3 jul. 2018.

TÚlIO COSTA, Caio. Ombudsman - o relógio de Pascal. São Paulo: Geração editorial, 2006.

VALENTE, Cesar. O entrevistão do Kucinski. De Olho na Capital. O blog do Cesar Valente. 25 jun. 2012. [Republicado de Diarinho]. Disponível em: http://www.deolhonacapital.com.br/2012/06/25/o-entrevistao-do-kucinski/. Acesso em: 7 jul. 2018.

Submetido em: 28.10.2019

Aprovado em: 26.01.2020 